\title{
Configuration Optimization for maximum load bearing capacity per unit weight of a Plane Truss using Exhaustive Searching approach
}

\author{
Umar Rashid \\ Assistant professor, Department of Mechanical Engineering, Islamic University of Science and Technology \\ Awantipora 192122 J\&K India. \\ Email: omer@islamicuniversity.edu.in
}

\begin{abstract}
Trusses are lightweight structures for supporting heavy loads. The location of joints to maximize the load bearing capacity for minimum weight is presented as an optimization problem. The optimization technique is demonstrated for a plane truss subjected to point load.The problem is solved in MATLAB to find the relative position of various truss members .Exhaustive searching method is utilized to obtain the optimum location of various members for the design. The location of only one of the joints is changed so as to present the problem in a single variable. The method can be extended to the design of a truss for the change in the location of more than one joint.
\end{abstract}

Keywords: Truss; Optimization; MATLAB; Exhaustive searching

\section{INTRODUCTION}

Optimal design of truss-structures has always been an active area of research in the field of search and optimization. Various techniques based on classical optimization methods have been developed to find optimal truss-structures. However, most of these techniques can be classified into three main categories: (i) Sizing, (ii) Configuration ${ }^{[6]}$ and (iii) Topology optimization

In sizing optimization technique the cross section of the members is taken as design variable while as the coordinates of nodes and the connectivity of the elements is kept fixed.In most studies, simultaneous optimization of sizing and configuration has been used $^{[8]}$. The resulting problem is a non linear problem with member area and change in nodal coordinates as variables

In the configuration optimization of trusses, the change in nodal coordinates is kept as design variables. In most studies, simultaneous optimization of sizing and configuration has been used. The resulting problem is also a non linear problem with member area and change in nodal coordinates as variables.

In the topology optimization ${ }^{[7]}$, the connectivity of members in a truss is to be determined. Classical optimization methods have not been used adequately in topology optimization, simply because they lack efficient ways to represent connectivity of members.
In the present study the configuration technique is used and the problem is presented in a single variable so as to determine the position of the joint for the maximum load bearing capacity. The truss to be designed is a nine member truss with an obstruction to clear so to present a constraint in the optimization problem. When the position of the joint is determined, the members of the truss are positioned accordingly so that the resulting configuration is the optimum configuration for the maximum load bearing capacity. Yet another variable in the design of the truss is weight of the truss which is to be minimized so that the cost of the truss is minimized. The resulting design is the optimum design. The exhaustive search approach is utilized and the problem is solved in MATLAB. The weight function of the truss is coupled with the load bearing capacity of the truss so as to determine the optimum position of the joint. Only the position of one of the joints is changed so to determine the relative position of the truss members.

\section{FORMULATION OF THE PROBLEM STATEMENT}

The truss is analyzed for a point load. The method can be generalized for any truss for any number of loads. The idea of the optimum design based on configuration is to obtain the relative positions of the various truss members so that the resulting configuration is the optimum one for the maximum load bearing capacity. The optimization problem is then solved and the 


\section{International Journal of Research in Advent Technology, Vol.7, No.2, February 2019 E-ISSN: 2321-9637 \\ Available online at www.ijrat.org}

constraints are produced by the availability of space, presence of an obstruction, maintaining some basic truss geometry ${ }^{[2]}$

The method of exhaustive search is demonstrated for the truss shown in figure (1). The joints are labeled as A through $\mathrm{F}$ and members are numbered as 1 through 9.All lengths are in inches and coordinates $(\mathrm{x}, \mathrm{y})$ of all joints except $\mathrm{B}$ are fixed. The coordinates of $\mathrm{B}$ are $(2, \mathrm{y})$ so that joint $\mathrm{B}$ is moved in upward direction along $\mathrm{y}$ axis to find the optimum location for maximum load bearing capacity. The specifications of the truss are Density of each member $=0.2836 \mathrm{lb} / \mathrm{in}^{3}$

Area of cross section of each member $=0.00307 \mathrm{in}^{2}$

Coordinates of the joints are given as

$$
\begin{array}{ll}
\left(\mathrm{x}_{\mathrm{a}}, \mathrm{y}_{\mathrm{a}}\right)=(0,0) & \left(\mathrm{x}_{\mathrm{b}}, \mathrm{y}_{\mathrm{b}}\right)=(2, \mathrm{y}) \\
\left(\mathrm{x}_{\mathrm{c}}, \mathrm{y}_{\mathrm{c}}\right)=(4,0) & \\
\left(\mathrm{x}_{\mathrm{d}}, \mathrm{y}_{\mathrm{d}}\right)=(2,2) & \left(\mathrm{x}_{\mathrm{e}}, \mathrm{y}_{\mathrm{e}}\right)=(1,2)
\end{array}
$$$$
\left(\mathrm{x}_{\mathrm{f}}, \mathrm{y}_{\mathrm{f}}\right)=(0,2)
$$

All members are made of steel and the truss is to clear an obstruction so that angle $\mathbf{P}$ and angle $\mathbf{Q}$ should be greater than $16^{\circ}$ and $21^{\circ}$ respectively. This produces the constraint equation for the optimization problem. The load $\mathrm{L}$ acting at the end is replaced by a unit load for the sake of simplifying the problem. This does not lead to the loss of information and any analysis for the unit load is valid for a general load. The entire analysis is done for a unit load. However as the optimization method utilized is based on the fractional loads in each member, this should not be taken as the analysis being performed on the load of $1 \mathbf{l b}$.

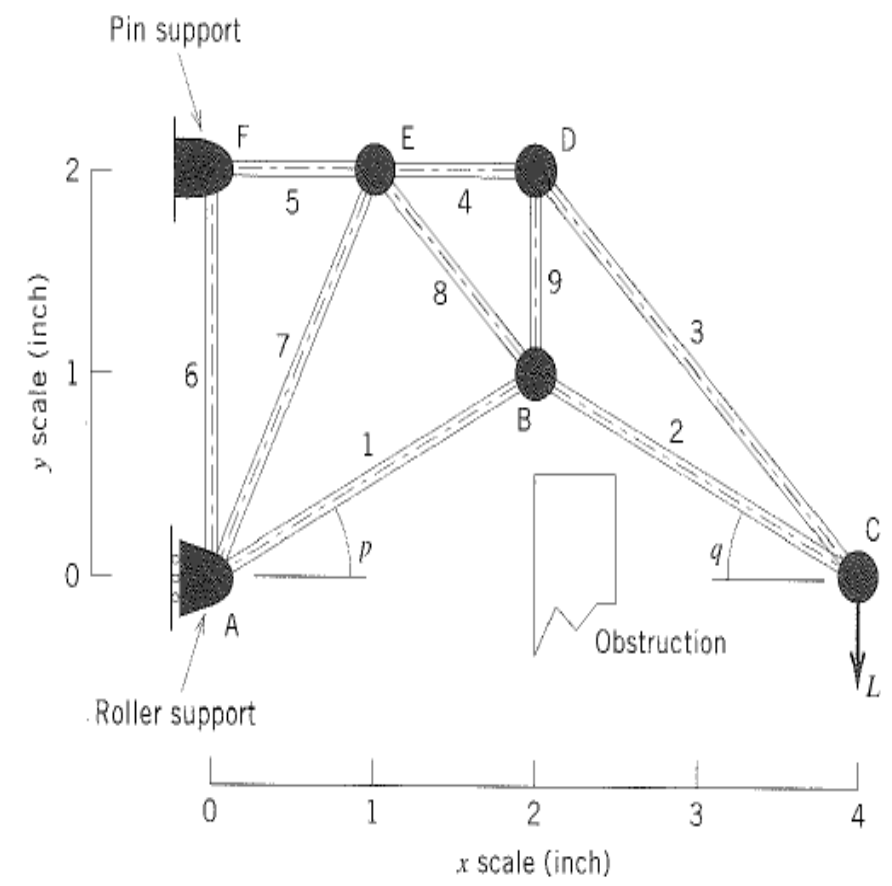

Fig 1: A nine member truss with a unit load at the end.

The location of joint $\mathrm{B}$ should be such that angle $\mathrm{P}$ should be greater than $16^{\circ}$ and no member in the truss should be less than 0.5 inches. This produces a constraint on the $y$ coordinate of the joint $B$. The objective of the design is to maximize load per unit weight of the truss ${ }^{[3]}$

$\Theta=\mathrm{L} /$

W. (1)

Where $\mathrm{L}$ is the load and $\mathrm{W}$ the weight of the truss The total weight of the truss is given by $W=.00087\left(11.06+\sqrt{(2-y)^{2}+1}+2 \sqrt{y^{2}+4}-y\right.$

The force in each member is found as a function of $y$ when joint B IS moved upwards. The constraint due to the obstacle is

Tan $\mathrm{p} \geq 16^{\circ}$ or $\quad 0.57 \leq \mathrm{y} \leq 1.5$

The truss is analyzed for a force of $\mathrm{L}=1 \mathrm{lb}$. The member forces in the truss are calculated using the method of joints and the fraction $Q_{m}$ of the force in each member is written as ${ }^{[4]}$

$\mathrm{Q}_{\mathrm{m}}=\mathrm{f}_{\mathrm{m}} / 250, \quad \mathrm{f}_{\mathrm{m}} \geq 0$

$\mathrm{Q}_{\mathrm{m}}=\left(\mathrm{f}_{\mathrm{m}} / 450\right)^{*}\left(\mathrm{r}_{\mathrm{m}}\right)^{2} ; \mathrm{f}_{\mathrm{m}} \leq 0$. 


\section{International Journal of Research in Advent Technology, Vol.7, No.2, February 2019 E-ISSN: 2321-9637 \\ Available online at www.ijrat.org}

Where $250 \mathrm{lb}$ is the tensile strength of steel for an area of $0.0307 \mathrm{in}^{2}$.For failure in compression the buckling formula is used that is given by ${ }^{[1]}$

$\mathrm{P}_{\mathrm{CR}}=\Pi \mathrm{E} \mathrm{I} / \mathrm{r}_{\mathrm{m}}{ }^{2}$.

$\mathrm{E}$ is the elasticity modulus, I the moment of inertia and $\mathbf{r}_{\mathbf{m}}$ is the length of the member.

The Fraction $\mathrm{Q}_{\mathrm{m}}$ of each force is given by the following equations; $\mathbf{Q} 1$ through $\mathbf{Q}_{9}$

$Q_{1}=\frac{3\left(y^{2}+4\right)^{1.5}}{450(y-4)}$

$Q_{2}=\frac{\left(y^{2}+4\right)^{1.5}}{450(2-y)}$

$Q_{3}=\frac{2 \sqrt{2}}{250(2-y)}$

$Q_{4}=\frac{2}{250(y-2)}$

$Q_{5}=\frac{2}{250}$

$Q_{6}=\frac{1}{250}$

$Q_{7}=\frac{10 \sqrt{5}(y-1)}{450(y-4)}$ For

$\mathrm{y} \leq 1$.

(9)

$Q_{7}=\frac{2 \sqrt{5}(1-y)}{250(y-4)} \quad$ For $\mathrm{y}$

$\geq 1$

(10)
$Q_{8}=\frac{\left((2-y)^{2}+1\right)^{1.5}[Y(y-1]}{450(y-4)(y-2)}$ For

$\mathrm{y} \leq 1$

$Q_{8}=\frac{\left((2-y)^{2}+1\right)^{0.5}[4(y-1]}{250(y-4)(y-2)}$ For

$\mathrm{y} \geq 1$.

$Q_{9}=\frac{2(2-y)}{450}$

(13)

The maximum external load $\mathbf{L}_{\text {max }}$ can be computed from

$\mathrm{L}_{\max }=\frac{1}{\max \left(Q_{m}\right)}$

Here $\max \left(\mathrm{Q}_{\mathrm{m}}\right)$ refers to the maximum value of $\mathrm{Q}$ for $0.57 \leq \mathrm{y} \leq 1.5$

And the objective function to be maximized can be written as ${ }^{[5]}$

$\Theta=\frac{1}{\max \left(Q_{m}\right)(W)}$

The procedure to maximize the objective function is hitherto devised. First the maximum value for each $\mathrm{Q}_{\mathrm{m}}$ is obtained in the given domain. Two domains are chosen for this purpose $0.57 \leq \mathrm{y} \leq 1.5$ and $0.767 \leq \mathrm{y} \leq$ 1.5.Next the objective function is maximized for the corresponding y value.

The controlling member for the first domain is the member 6 and for second domain is member 7.The optimal location of the joint $\mathrm{B}$ is the initial location for both the domains.

\section{RESULTS}

The weight function is represented as a function of $y$ in figure 1. Next Q1, Q2, Q3 up to Q9 are plotted as shown in figure 2.Then objective function is plotted for nine members figure (3) and figure (4) . The maximum value of the objective function is then obtained from the graph. 


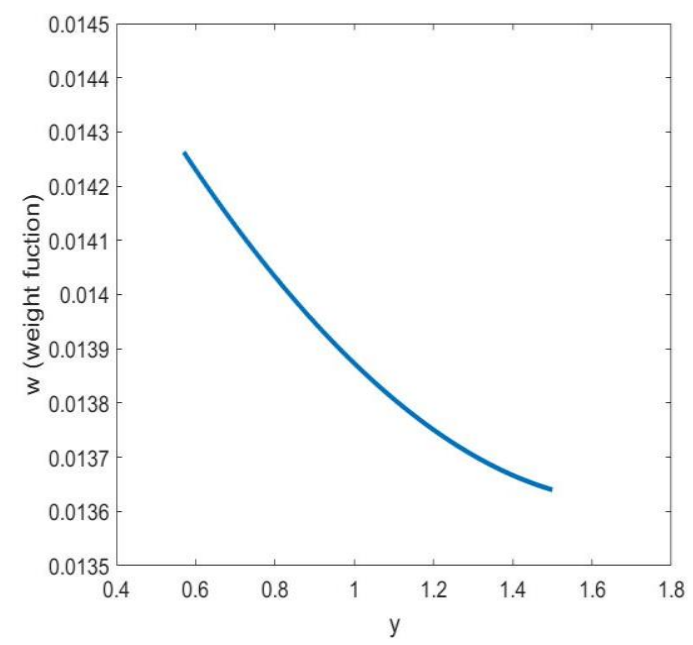

Fig 1: Weight function as a function of $y$

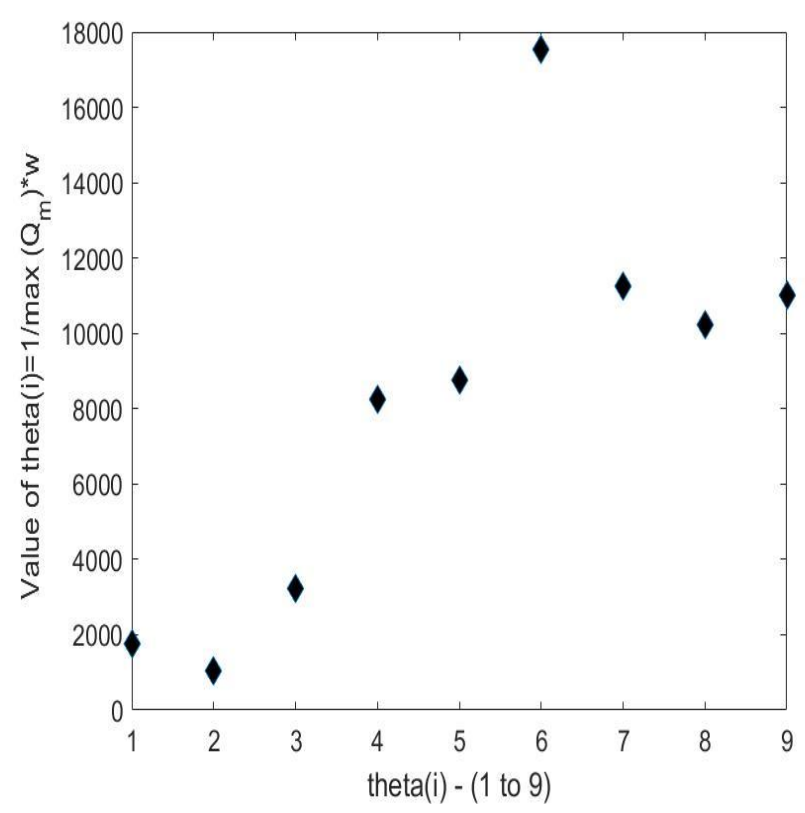

Fig 3: The value of Objective function $\theta$ for each member of the truss $; 0.57 \leq \mathrm{y} \leq 1.5$

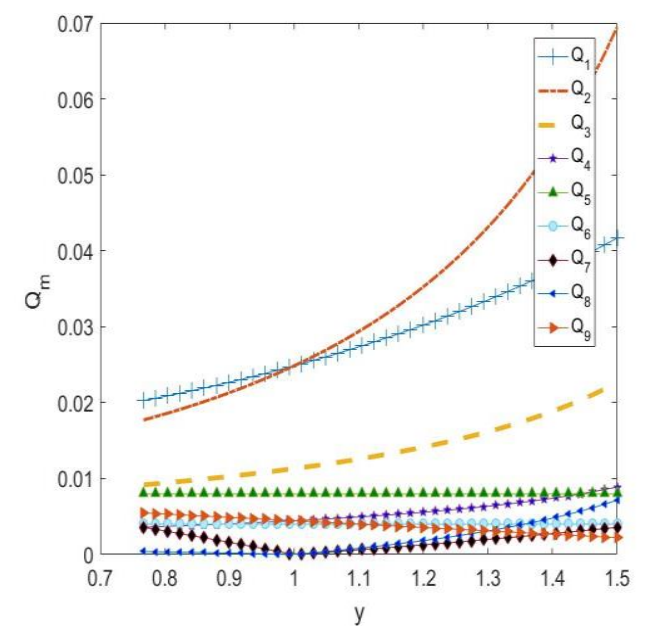

Fig 2: $Q_{m}$ as a function of $y$.

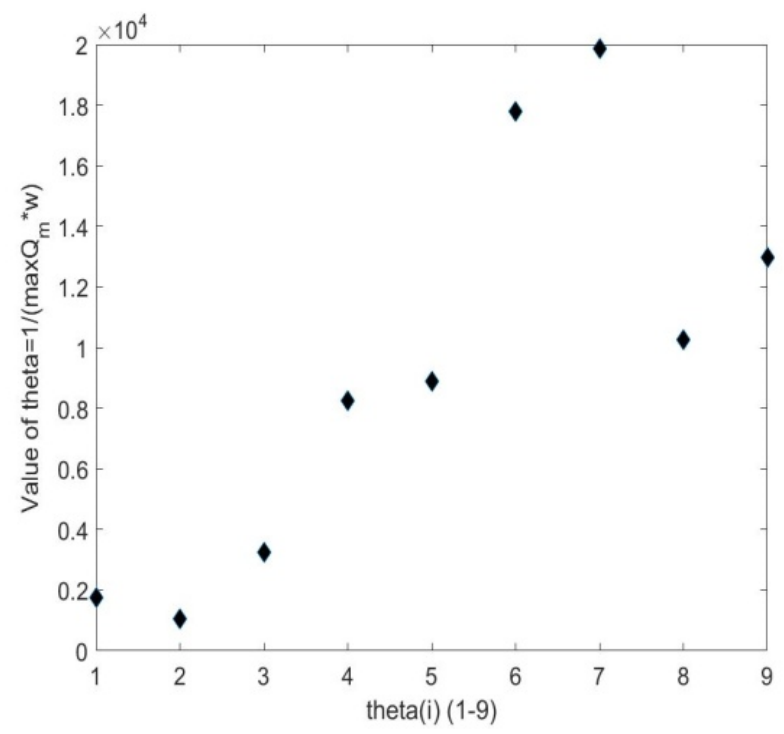

Fig 4: The value of objective function $\theta$ for each member of the truss $0.767 \leq y \leq 1.5$

\section{CONCLUSION}

The method of finding the optimal location of the one of the joints for a plane truss is demonstrated. The method can easily be extended for optimizing the location of more than two joints. It is demonstrated that Load bearing capacity per unit weight is maximum at one particular location of joint. The constraint equation for the truss has given the small space for the domain. The exhaustive search method using the software MATLAB is used to maximize the objective function. It is also demonstrated that 
International Journal of Research in Advent Technology, Vol.7, No.2, February 2019

E-ISSN: 2321-9637

Available online at www.ijrat.org

MATLAB can act as an efficient tool for solving the structural optimization problems including trusses.

\section{REFRENCES}

[1]Andre,P. and Singer,1.(1998).Strength of materials AWL publications.

[2] gere and Timoshanko, Mechanics of solids(2004) Mir Publishers Moscow

[3] Edwin, K.P.Stansilaw,H.Zak(2013).Introduction to Applied optimization; Multi-disciplined view of Optimization.

[4] Peter W.C (2004).Two dimensional shape optimization and stiffness optimization of distributed parameter systems; Springer Verlog.
[6] Polheim H 1998 Genetic and evolutionary algorithm toolbox for use with MATLAB. Technical Report. Technical University Ilmnau .

[7] Allwood, R.J., Chung, Y.S., 1984. Minimumweight design of trusses by an optimality criteria method. International Journal for Numerical Methods in Engineering 20, 697-71

[8] Zhu.B.F, Li.Z.M, Zhang .B.(1984).Principle and Applications of Structural Optimization; Waterpower publisher ,Beijing.

[9] Tugrul Talaslioglu Global stability-based design optimization of truss structures using multiple objectives Sadhan a Vol. 38, Part 1, February 2013, pp. 37-68. c Indian Academy of Science 